\title{
Compliance and Audit Necessary for Effective Statutes Protecting Student Athletes from TBI Related Injuries in California
}

\author{
Robert A. Bitonte and Michelle Gutierrez Harris* \\ Case Western Reserve University School of Law, Cleveland, Ohio, USA \\ *Corresponding author: Michelle Gutierrez Harris, Email: michelleann.gutierrez@gmail.com
}

Received: July 10, 2019; Accepted: July 19, 2019; Published: July 22, 2019;

\begin{abstract}
Awareness of mild traumatic brain injury in sports in the United States of America has had a dramatic increase in the past several years. This article cites recent developments in its increased awareness, and some recent legal developments regarding the medical condition. This commentary recommends an additional part of legislation the authors feel to be effective in protecting the susceptible.
\end{abstract}

\section{Illustrating the Problem of TBI}

Traumatic Brain Injury (TBI) is defined as a traumatically induced structural injury and/or physiological disruption of brain function as a result of an external force that is induced by new onset of at least one of the following clinical signs. Immediately following the event: any period of loss of decreased level of consciousness, any loss of memory for events immediately before or after the injury, any alteration in mental state at the time of the injury (confusion, disorientation, slow thinking), neurological deficits (weakness, loss of balance, change in vision, paresis/paraplegia, sensory loss aphasia that may or may not be transient), and/or intracranial lesion.

Traumatic brain injury is categorized as mild, moderate or severe depending on certain criteria. A mild categorization is determined when the structural imaging is normal, the loss of consciousness is ranges between 0-30 minutes, the alteration of consciousness ranges between a moment up to 24 hours, the post traumatic amnesia is less than or equal to 1 day, and the Glascow Coma Scale is between 13-15. A moderate categorization is determined when the structural imaging is normal or abnormal, the loss of consciousness exceeds 30 minutes but last less than 24 hours, the alteration of consciousness exceeds 24 hours, the post traumatic amnesia is greater than 1 day but less than 7 days, and the Glascow Coma Scale is between 9-12. A severe categorization is determined when the structural imaging is normal or abnormal, the loss of consciousness exceeds 24hours, the alteration of consciousness is analyzed under other criteria, the post traumatic amnesia exceeds 7 days, and the Glascow Coma Scale is between 3-8 [1].

While Eighty-five percent of medically treated traumatic brain injuries are determined to be "mild", this designation of "mild" is dangerously misleading because there is a small but significant subpopulation in this group that has persistent and catastrophic lingering effects. Binder \& colleagues (2009 \& 1997) [2,3], analyzed a meta-analysis of data from eight studies of long-term (3 months to many years after injury) effects of $\mathrm{mTBI}$, and reported that approximately $8 \%$ of individuals remained symptomatic chronically and $14 \%$ had work-related disability ${ }^{2,3}$. Binder and colleagues (2009 \& 1997) [2,3] discussed a prior study by Bohnen et al (1994) [4], which emphasized that though the symptoms of mTBI are nonspecific, it is likely that the severity of the symptoms is greater after mTBI than in control subjects and some patients have cognitive deficits which are apparent only in particular stressful situations $[2,3]$.

Not only is the finding of an mTBI injury potentially catastrophic, but the enormous incidence rates making it one of the most costly conditions in the USA. The incidence rate of mTBI in America is projected to be 1.5 million -3.8 million annually. In the wider perspective of the world, the incidence is cited to be 9.5 million - 50 million per year. While a study by Rutland-Brown et al. (2006) [5] cited that the CDC estimated a total medical cost of $\$ 16.7$ billion for mild TBI in the USA, these estimates overlook those who do not seek care in hospitals or emergency departments or choose not to seek care at all [5]. More importantly, medical costs are not the only costs incurred, as work loss costs have been estimated to be $\$ 69.2$ billion and the value of lost quality of life is estimate to be $\$ 137$ billion. Hence, the totality of costs suffered due to TBI in the USA alone is estimated to be $\$ 221$ billion annually.

\section{Proposed Legislative Remedies to Regulate TBI in Sports}

A big impetus to this increased regulation and legislation was because of unfortunate consequence consequences of a TBI suffered by Zackery Lystedt, a 13 year old football player who was permanently disabled after sustaining a concussion in 2006 and prematurely returning to the game. Zackery Lystedt was a remarkable athlete who played both offense and defense on his junior high school football 
team. After tackling an opponent, Zackery's head struck the ground. Despite the blow, he was back in the game by $3^{\text {rd }}$ quarter. However, Zackery collapsed on the field and was airlifted to Harborview Medical Center where he underwent emergency surgery to remove the left and right site of his skull to relive the pressure from his injured and swelling brain. Although this procedure saved his life, he experience severe brain injury, spent seven days on a ventilator and spent three months in coma before he woke up in a his new reality. It was nine months before Zackery was able to speak his first words and nearly three years before he was able to stand with assistance. Today, Zackery continues to depend on a wheelchair and spends numerous hours each week in rehabilitation.

Three years following Zackery's injury, in May 2009, the state of Washing passed a new bill referred to as the Lystedt Law, which protects young athletes from life threatening or potentially life-long consequences that can result from prematurely returning to the game following a concussion. The Lystedt Law requires any youth showing signs of a concussion to be examined and cleared by a licensed health care provider before the young athlete is allowed the return to play. Less than five years following Washington's passing of the law, all 50 states and the District of Colombia have adopted the majority of the core principles of the Lystedt Law, making the Lystedt Law the fastest growing public safety initiative to become law in all states [6].

With the support of key national organizations, including the NFL, CDC, USA Football, and the United States Brain Injury Alliance, the Lystedts are striving to bring the law to the US Congress and establish the return to play safeguards are federal law.

\section{Additional Protective Legislation in California}

Assembly Bill No. 2127 was signed by the governor on July 21, 2014. This added section 35179.5 to the California Education code [7]. This legislation limits the amount of full contact practices as well as specific requirements in the care of athletes suspected of having a mild TBI. For example, section 49475 [8] of the California Education Code is amended to read:

49475. (a) If a school district, charter school, or private school elects to offer an athletic program, the school district, charter school, or private school shall comply with both the following:

(1) An athlete who is suspected of sustaining a concussion or head injury in an athletic activity shall be immediately removed from the athletic activity for the remainder of the day, and shall not be permitted to return to the athletic activity until he or she is evaluated by a licensed health care provider. The athlete shall not be permitted to return to the athletic activity until he or she receives written clearance to return to the athletic activity from a licensed health care provider. If the licensed health care provider determines that the athletic sustained a concussion or a head injury, the athlete shall also complete a graduated return-to-play protocol of no less than seven days in duration under the supervision of a licensed health care provider. The California Interscholastic Federation is urged to work in consultation with the American Academy of Pediatrics and the American Medical Society for Sports Medicine to develop and adopt rules and protocols to implement this paragraph.

(2) On a yearly basis, a concussion and head injury information sheet shall be signed and returned by the athlete and the athlete's parent or guardian before the athlete initiates practice of competition.

(b) A sued in this section, "licensed health care provider" means a licensed health care provider who is trained in the management of concussions and is acting within the scope of his or her practice.

(c) This section does not apply to an athlete engaging in an athletic activity during the regular school-day or as part of a physical education course required to pursuant to subdivision (d) of Section 51220.

\section{Comment}

Although it is hoped that legislation, statutes, and laws are adhered to, without enforcement, at least intermittent enforcement seems to have a positive effect of compliance with laws.

The authors of this commentary feel that for this law to be as effective as hoped and should be, an audit of compliance should be written into the legislation on a yearly or every two years. If noncompliance is found, Draconian measures such as forfeiture of wins, loss of championships, and cancelling of future schedules should be implemented to note the seriousness of the consequences of the violations of these statutes.

\section{References}

1. Teasdale G, Jennett B (1974) Assesment of coma and impaired consciousness: a practical scale. Lancet 2: 81-84.

2. Binder LM, Iverson GL, Brooks BL (2009) to err is human: "abnormal" neuropsychological scores and variability are common in health adults. Arch Clin Neuropsychol 24: 31-45.

3. Binders LM (1997) A review of mild head trauma 2: Clinical implicaitons (review) J Clin Expt Neuropsychol 19: 432-457.

4. Bohnen N, Twijnstra A, Jolles J (1993) Persistance of postconcussional symptoms in uncomplicated, mildly head-injured patients: a prospective cohort study. Neuropsychiatry Neuropsychol Behav Neurol 6: 193-200.

5. Rutland-Brown W, Langlosi JA, Thomas KE, et al. (2003) Incidence of Traumatic Brain Injury in the United States. J Head Trauma Rehabilitation 21: 544-548.

6. https://www.nlelaw.com/case-results/zackery-lystedt-law

7. https://codes.findlaw.com/ca/education-code/edc-sect-35179-5.html

8. https://law.justia.com/codes/california/2011/edc/title-2/49470-49475/49475/

\section{Citation:}

Bitonte RA and Harris MG (2019) Compliance and Audit Necessary for Effective Statutes Protecting Student Athletes from TBI Related Injuries in California. Integr J Orthop Traumatol Volume 2 (4): 1-2. 